\title{
THE EXPERIMENTAL RADIOGRAPHY OF SMALL FRAGMENTS OF GLASS IN RELATION TO THE HUMAN EYE
}

BY

\section{R. U. GillaN}

WALSALL AND WEST BROMWICH

THE object of this experiment was to discover whether or not, small fragments of various kinds of glass were opaque to X-rays in conditions approximating to those which would obtain supposing such a fragment to be in the eye or orbit, and to be the subject of radiography.

The subject appeared to me to be of some importance, in view of the widespread use of glass, its vulnerability, and the frequent circumstances in which particles of it may enter the eye, especially in modern war-time conditions. The prevailing opinion appears to be that, whilst lead glass is certainly opaque, it is doubtful whether other kinds are. Thus, Parsons (1934) states that particles of glass commonly fail to reveal their presence in the skiagram, except heavy lead glass, and in a text book edited by Shanks, Kerley and Twining (1939), it is stated that chips of glass may cast a shadow, but that spicules of lead glass certainly will. Baker (1937) refers to the difficulties of radiography when the foreign body is some comparatively radio-translucent substance, such as glass or wood.

The matter was brought to a head by my having a case of retained foreign body of the eye, suspected of being glass from the history, but suspected of not being glass by an ophthalmologist of very great experience, on account of its being opaque to X-rays. Doubts were also expressed on the subject by an ophthalmic radiographer, with very many years of experience in the interpretation of X-ray plates. He did, however, incline to the view that the opacity was caused by glass. Subsequent experience proved the foreign body to be indeed glass, the fragment being removed from the eye at operation.

The mode of conducting the experiment was as follows. Various specimens of glass, 14 in number, were selected. A piece of each was taken in turn, covered by two layers of gauze, placed on a piece of cardboard, on a table, and hit smartly with a wooden mallet. The result was fragmentation, and of the fragments were selected three, measuring as nearly as possible in thickness, $2 \mathrm{~mm}$., $1 \mathrm{~mm}$., and $\frac{1}{2} \mathrm{~mm}$. respectively, measurements being made by calipers having a large degree of accuracy, and measuring to within $1 / 10 \mathrm{~mm}$. These were now taken and fixed at equidistant intervals on a small square of dental wax. The piece of wax was then fixed 
in position over the front of the closed eyelids by means of a bandage, in such a way that the three fragments were opposite the orbital opening. The subject's head was placed facing downwards over a casette, and an exposure of 2 seconds was made with the X-ray tube above the occiput, at a distance of 20 ins. from the film, and using a kilo-voltage of 55. This exposure therefore was made through the whole diameter of the skull. The piece of wax was then placed sagitally, in such a way that the three fragments of glass were in close apposition to the inner aspect of the eye, the eyelids being open. A dental film was placed in a similar position on the nasal side, and an exposure made with the $\mathrm{X}$-ray tube on the temporal side of the skull, at a distance of 14 ins., and in such a way as to obtain a bone-free picture of the eye. In this exposure a kilo-voltage of 50 was used. I wish to express my thanks to Sister Burrows, of the X-ray Dept. of the West Bromwich and District Hospital for her co-operation in the conduct of the experiment.

The purpose of the two exposures, was in the first, to demonstrate the effect in the case of the rays passing through the thickness of the skull and the eye and eyelids, and in the second, of their passage through the soft tissues of the eye and eyelids only.

It is admitted that in the case of the second exposure, the X-ray film is much closer to the fragments of glass than would obtain in an actual case of retained foreign body. The same objection does not, however, hold good in the case of the first exposure, where the distance of the fragments from the film is much greater and approximates more to the conditions which would obtain in an actual case. The distance was about 2 ins. It seemed to me that the conditions of the experiment were as near reality as possible in a human subject.

The list of glasses chosen include those most commonly in use, namely various window glasses, spectacle glass, glass used in motor car windscreens, and bottle glass. They are tabulated below.

\begin{tabular}{|c|c|c|c|}
\hline Group A & $\begin{array}{l}1 \\
2 \\
3\end{array}$ & $\begin{array}{l}24 \text { oz clear. } \\
\text { t-in. polish plate. } \\
\frac{1}{8} \text {-in. rough roll. }\end{array}$ & $\begin{array}{l}\text { Specimens of domestic } \\
\text { and shop window glass } \\
\text { kindly supplied by a local } \\
\text { firm. }\end{array}$ \\
\hline Group B & $\begin{array}{l}4 \\
5 \\
6 \\
7 \\
8\end{array}$ & $\begin{array}{l}\text { Crown spectacle glass. } \\
\text { Crookes glass A.2. } \\
\text { London smoke glass. } \\
\text { Salvoc safety glass. } \\
\text { Welders blue. }\end{array}$ & $\begin{array}{l}\text { Specimens of spectacle } \\
\text { glass kindly supplied by } \\
\text { Messrs. C. Davis Keeler, } \\
\text { through Mr. Saward. }\end{array}$ \\
\hline Group C & $\begin{array}{r}9 \\
10 \\
11\end{array}$ & $\begin{array}{l}\text { Toughened safety glass (Triplex). } \\
\text { Laminated safety glass (Triplex). } \\
\text { Armour Plate glass (Pilkington). }\end{array}$ & $\begin{array}{l}\text { Specimens of motor wind- } \\
\text { screen glass kindly sup- } \\
\text { plied by Messrs. Triplex, } \\
\text { and Messrs. Pilkington of } \\
\text { Birmingham. }\end{array}$ \\
\hline Group D & $\begin{array}{l}12 \\
13 \\
14\end{array}$ & $\begin{array}{l}\text { Green bottle glass. } \\
\text { Brown bottle glass. } \\
\text { White bottle glass. }\end{array}$ & $\begin{array}{l}\text { Specimens of bottle glass } \\
\text { picked at random. }\end{array}$ \\
\hline
\end{tabular}


EXPERIMENTAL RADIOGRAPHY

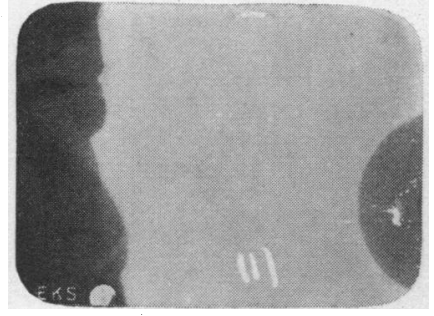

No. 1.

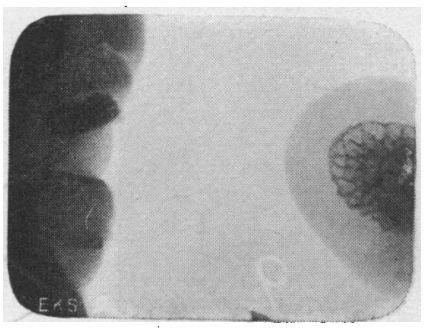

No. 9.

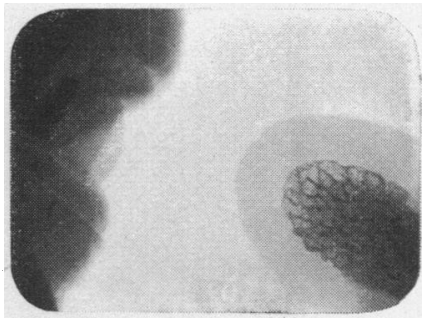

No. 8.

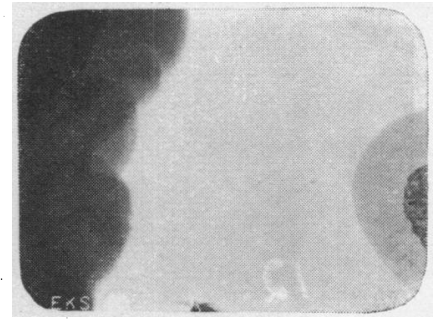

No. 12.

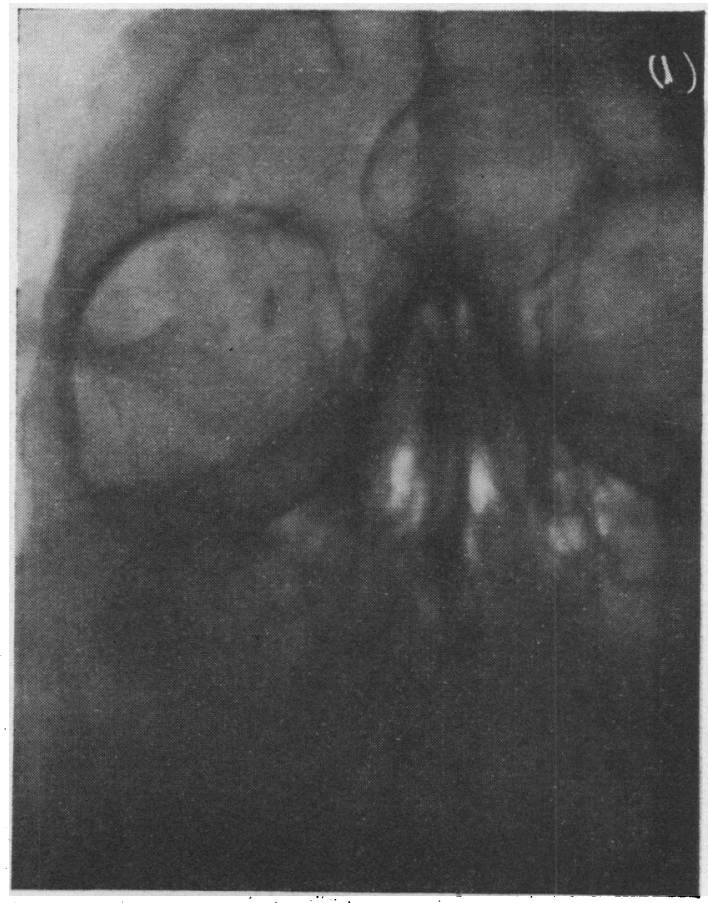

No. 


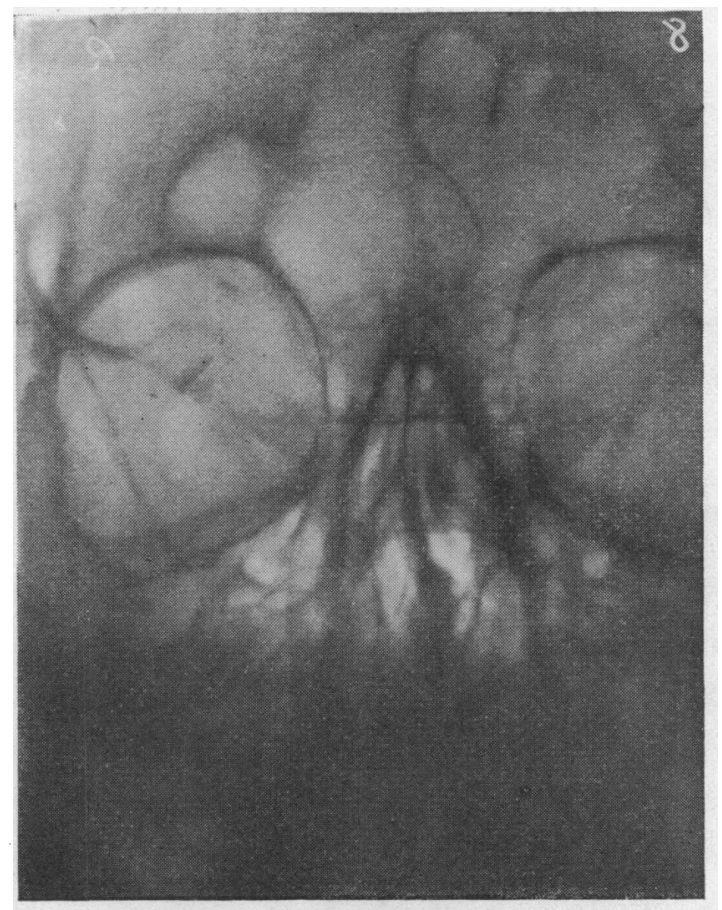

No. 8.

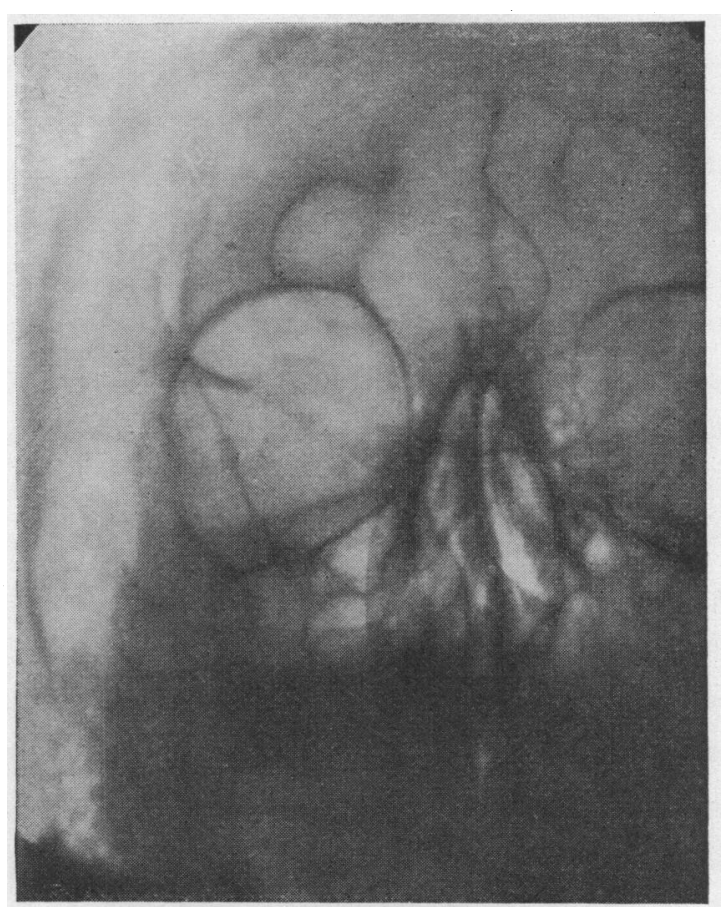

No. 9.

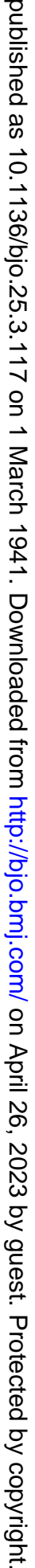




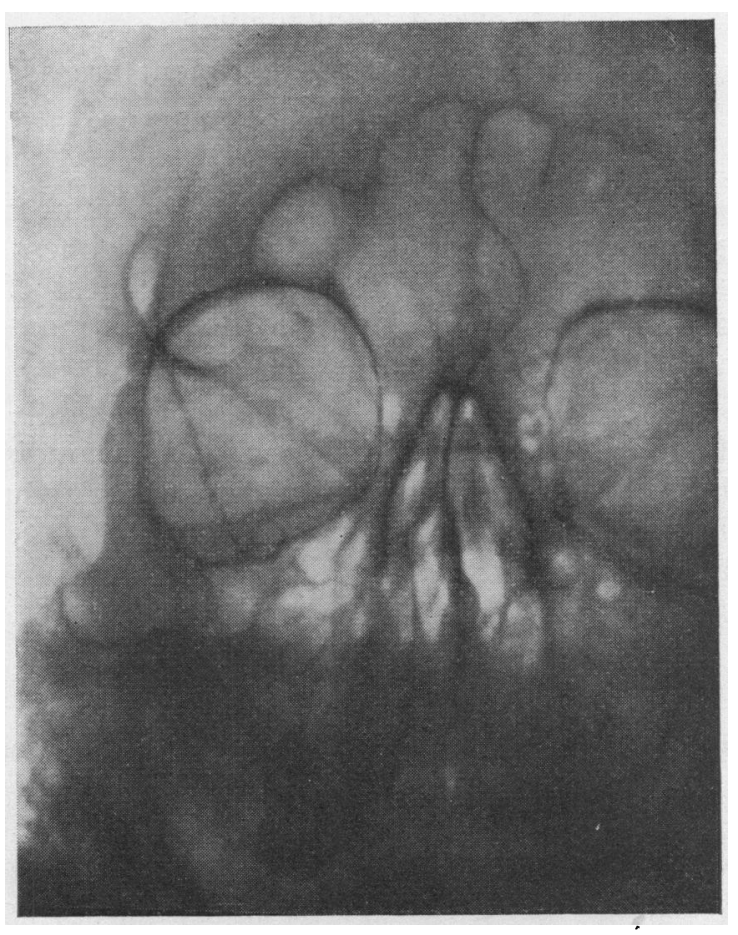

No. 12.

The result of the experiment was the discovery that all pieces of glass of whichever thickness used showed up on X-ray, both on antero-posterior and on lateral bone-free exposure, the $2 \mathrm{~mm}$. pieces showing the most clearly and the $\frac{1}{2} \mathrm{~mm}$. the least clearly, as one would expect. Some of the $\frac{1}{2} \mathrm{~mm}$. fragments were somewhat difficult of detection in the antero-posterior exposures, but a comparison of the exposed film with the corresponding specimen mounted on dental wax showed that a shadow could be detected in all cases, corresponding in position with the $\frac{1}{2} \mathrm{~mm}$. fragments. Specimens of $1 \mathrm{~mm}$. and $2 \mathrm{~mm}$. thickness were easily detected. Specimen No. 5 (Crookes A.2) threw the densest shadow. Other specimens showed a lesser density of shadow, and no great variation in respect of this, existed among them.

One radiograph from each group is reproduced as a matter of interest, and to give some idea of the density of shadow produced. These are :

$\left.\begin{array}{cccc}\text { Group } & \text { A } & \text { No. } & 1 \\ , & \text { B } & \text { No. } & 8 \\ , & \text { C } & \text { No. } & 9 \\ , & \text { D } & \text { No. } 12\end{array}\right\} \begin{aligned} & (24 \text { oz. clear domestic window glass.) } \\ & \text { (Welders Blue.) } \\ & \text { (Toughened Safety Glass ) } \\ & \text { (Green Bottle Glass.) }\end{aligned}$




\section{Practical Conclusions}

Conclusions emerging from this experiment are as follows.

(1) That most kinds of glass in common use are opaque to X-rays.

(2) That small fragments of the order of $\frac{1}{2}-2 \mathrm{~mm}$. in thickness show an opacity when exposed through the thickness of the eye and eyelids, and in addition through the thickness of the skull, but that fragments of under $1 \mathrm{~mm}$. in thickness may be difficult of detection in such conditions.

(3) It may be concluded that pieces of glass actually in the eye or orbit and exposed to X-rays under comparable conditions would also show, but that having regard to the somewhat greater distance of the foreign particles from the film in such a case, fragments of under $1 \mathrm{~mm}$. in thickness would a fortiori, be difficult of detection.

\section{Summary}

The object of the experiment is stated and the reasons given which led to its inception.

The details and mode of conduct are described.

The limitations of the experiment are discussed.

A classified list of the glasses used in the experiment is given.

The results of the experiment are given, and the practical conclusions are drawn, which appear to emerge therefrom.

\section{REFERENCES}

1. Parsons.-Diseases of the Eye. Seventh edition, p. 431.

2. Shanks, Kerley and Twining (1938). - A Text-book of X-ray Diagnosis, Vol. III, p. 746.

3. BAKER (1939). - Kadiography. October, 1937, p. 140.

\section{A SIMPLE OPTICAL APPLIANCE FOR USE WITH RESPIRATORS}

BY

$$
\begin{aligned}
& \text { P. Kinmont, M.D., F.R.C.S.Ed., A.D.M.S., E.M.S. } \\
& \text { newark-on-trent }
\end{aligned}
$$

THEIRE must be many hypermetropic presbyopes like myself, who have sought in vain for spectacles to wear inside the general service and civilian duty respirators which permit clear vision for reading and writing messages etc. 